\title{
Construction scale of stigma anxiety among a sample of Adolescents for prostitute mothers
}

\author{
Hossam A. M. Abo Saif, ${ }^{1}$ \\ Ibn Sina National College -Kingdom of Saudi Arabia
}

Received: $27^{\text {th }}$ Aug 2020 Revised: $4^{\text {th }}$ Sept 2020 Accepted: $9^{\text {th }}$ Sept 2020 DOI: https://doi.org/10.31559/CCSE2020.1.1.2

Abstract: This study aims to build (design) stigma scale for some adolescents whose mothers are a prostitute. In order to achieve this goal, the researcher constructed a scale of stigma Anxiety. The scale was applied to a sample of 28 adolescents, (19 males and 9 females), after confirming that they belong to prostitutes' mothers. Items of measurement consist of (36) items after reaching to adjust psychometric properties of the scale of validity and reliability to be capable of use. The results showed the possibility of using the detect stigma anxiety scale among adolescents of prostitute mothers. The results also showed there are no statistically significant differences in the stigma of anxiety among adolescents of prostitute mothers due to gender (males and females). However, there were statistically significant differences between the rural residents and urban residents in the sample of adolescents of prostitute mothers in favour of rural residents. The researcher recommended using the scale in future researches.

Keywords: Anxiety; Stigma; Adolescents; Prostitutes.

1 Corresponding author

Hossam A. M. Abo Saif

Ibn Sina National College, Saudi Arabia

E-mail: hossam.saif2020@gmail.com 
International Journal of Childhood, Counselling, \& Special Education (CCSE), Volume1, Issue: 1 , September: 2020, pp.11-38

\section{Introduction}

When the body is permitted, and it becomes a commodity that can be consumed and paid for, only then when all ethics of humanity, which are supposed to be present between a man and a woman, becomes violated and the sexual relation becomes business from which wealth could be gained in return of ruining the sanctity of body and soul. And in nowadays' world, there is no place for those who have no entity or worth.

The world of human relations enforces a model of interactions that matches the recent era which is mostly characterized by showing off the abilities, skills and personality structures in a way that makes these relations become based on equality \& not opposition or hostility. The nature of this era pushes individuals to take the route which makes them cherish and emphasis their dignity in addition to feeling their pride, glory and being of great value. Youth, on the other hand, have strong potentials stored within the depth of their not fully-created personalities. How will they be like if they lost these values, their psychological security and reputation threatened and was proclaimed to be a shame?

If we discuss the term "Stigma", we will find an agreement between (Lorenz, 2006, p. 10) and (Al-Quasir, 2011, p. 14) upon the history of the use of this term. As Greeks used burning and cutting off of parts of the body as a sign of being a criminal or a trader.

Heredia (2014, p. 525) also explained that "The Stigma" phenomenon is considered as a dangerous social disease that threatens the entity of individuals, families and the entire society. During the time through which man has made great scientific and technological achievements, he was not capable of eliminating social injustice which shows clearly in illiteracy, poverty \& illness. From this point it is clear that social relations and support are considered from the important sources of security needed by mankind.

(Kidir, B.H, 2011, p. 858) added that "Stigma" is nether abstract nor is it over sensitivity. However, it is a form of social injustice towards Stigma sufferers.

\section{Case Study}

The prostitution disaster is considered a dangerous social and psychological illness that threatens the entity of individuals, families and the entire society. There is no doubt that all members of the family, which includes a person that commits this crime, feel shamed and suffer from stigma; especially if this person was the mother whom was meant to be the cornerstone and the symbol of sacrifice and dedication. Particularly 
International Journal of Childhood, Counselling, \& Special Education (CCSE), Volume1, Issue: 1, September: 2020, pp.11-38

from the perspective of the Egyptian society which most of its members are followers of Islam which forbids prostitution, as well as most of the other religions. Moreover, stigma holders and their families are mostly marginalized, excluded and sometimes discriminated.

The term "Stigma" has its meaning derived from the physical significance of the word which is "scar" or "permanent sign" which is something that cases deformation to the body or the skin. Correspondingly, stigma is no more than a sign of belittling of the social status. So, the aim of this study is building up stigma anxiety for adolescents whose mothers took up prostitution. It also seeks answers for the following questions:

1) What is the validation of the Stigma Anxiety Scale with its different dimensions in the indication of prostitute mothers?

2) Does the degree of stigma anxiety for adolescents differ with the difference in gender and place of residence?

3) What are the dimensions and measures of Stigma Anxiety Scale according to the global analysis?

\section{Aim of Study}

The current study aims at:
1) Reaching to a regulated Arab tool to indicate the Stigma Anxiety for adolescents of prostitute mothers; and include it in the Arabic Library.

2) Exploring of the dimensions and contents of Stigma Anxiety for adolescents of prostitute mothers through studying the psychometric characteristics for the suggested scale.

3) Adjusting significant value for the Stigma Anxiety Scale based on the following variables:

- Gender (male - female)

- Place of residence ( rural areas - urban areas)

\section{Importance of the Study}

The importance of this study can be observed from both the theoretical and practical perspective.

\section{$1^{\text {st }}$ : The Theoretical Importance}

1) The study discusses one of the most vital subject for researching psychology, criminalistics and legitimacy science; which is prostitution.

2) Enrichment of the scientific library with a new research studying a sensitive and important category which is prostitute mothers.

3) Providing scientific information about Stigma Anxiety and prostitutes, with 
International Journal of Childhood, Counselling, \& Special Education (CCSE), Volume1, Issue: 1, September: 2020, pp.11-38

explanation of the hidden reasons behind slipping into this inappropriate disease affects the adolescents.

4) This study is considered one of the first studies, as far as known by the researcher, that took up building of a scale of Stigma Anxiety for the current sample for the research which is prostitute mothers.

\section{$2^{\mathrm{n}}$ : The Practical Importance}

1) The study helps in acknowledging the dimensions contributing in the formation of Stigma Anxiety for adolescents of prostitute mothers. Consequently, the study grabs the attention to these dimensions, their importance and their capability of causing this manner.

2) the study helps correlating prostitution of the mothers with other dimensions that may be the cause of this manner

3) encouraging other researchers interested in research Varity to study different cases related to prostitute mothers

4) Ability of researches to benefit from acknowledging different problems related to prostitution

\section{Term of study}

\section{$1^{\text {st }}$ : Scale definition}

(Mclntire \& Miller, 2000, p. 373) defines the scale as the tool used to measure some of the personality characteristics which is considered important in the description and the full understanding of the manner $\mathrm{m}$ which requires $s$ certain actions to me made by the examined case.

(Najd, 2016, p 240) gave another definition to the scale as being a gradual chain of actions in the form of verbal situations that has been chosen randomly to measure certain amounts of the manner indicating the characteristic meant to be measured

\section{$2^{\text {nd }}$ : Anxiety Definition}

Anxiety is a state of undefined severe fear that possess a person causing this person to experience high levels of pain enclosure and sadness and it is a painful experience through which the sufferer is expected to be endangered or to be uncomfortable in the surrounding or at the person work place (Galm \& Mesum , 2017 ,p. 81)

\section{$3^{\text {rd }}$ : Stigma Definition}

According to (Greffman E., 1963, P. 5) Stigma is a description that shames a man and deforms his image deeply and it is often bad feeling that gets stuck to a person and acts as an obstacle in the path of an undiminished social life. Stigma is measured in degrees on the stigma scale. 
International Journal of Childhood, Counselling, \& Special Education (CCSE), Volume1, Issue: 1 , September: 2020, pp.11-38

\section{$4^{\text {th }}:$ Stigma anxiety}

Due to the absence of a specific definition to stigma anxiety the researcher defined it based on the previous theories and the theoretical definitions of stigma and anxiety as a mysterious feeling or a state of observing and fear featured with high levels of tension for adolescents subjected to the shame caused by the inappropriate actions of their mothers. He also defines it as an unpleasant reactive experience related to stigma, scandal and shame , and the extreme fear of reflecting the shame on the adolescents own lives when facing people and during dealing with them. It is measured according to the degree the adolescent scares during his respond to the stigma anxiety scale.

\section{$5^{\text {th }}$ : Prostitution Definition}

Rachel .M \& Melissa .F (2019, p. 5) defined it as immoral sexual manner committed by a man or a woman for the sake of ongoing pleasure and satisfying the sexual need. The prostitution based sexual relations are temporary and in return to a certain amount of money. In other words buying the woman body in return for a specific price with absence of love, respect and mutual feeling between the couple performing the sexual relation

\section{$6^{\text {th }}$ : Prostitute definition}

The prostitute is a female involved in sex relations with any person in return of a price and she accepts this regular behavior without any differentiation (Ana. M., 2014, p. 5)

\section{Theoretical Study Frame}

\section{$1^{\text {st }}$ : Meaning Of Stigma}

World health organization (WHO, 1984) defined stigma as a sign of shame and embarrassment and rejection, which is attached to people through being rejected from others and insulting them which may lead to isolation which causes discrimination and prejudice and annoyance.

Stigma can also be defined as a negative situation developed in members of society against specific group of its members towards a particular individual and it includes Believes, judgments and behaviors which lead to criminalization against the shamed person. (Cecilia B., et al, 2017 , p. 74) also defines it as a scar in morals or a defect in the characteristics.

It is very clear from the previous explanation that there is disrespect towards a person from different people or a certain group, and it refers to any negative procedure or rejection to unaccepted difference that a person is defined with which forbids this person from social support or acceptance due to being different on the physical, behavioral, social or psychological basis. 
International Journal of Childhood, Counselling, \& Special Education (CCSE), Volume1, Issue: 1 , September: 2020, pp.11-38

Al kaseer (2011, p. 16)agrees with Hinshaw (2007, p. 21) in the definition of Stigma as for being a negative mental vision that gets attached to a person as a means of expressing annoyance or belittling towards that person, as a result of the person's performance of an abnormal behavior that defies the morals and standards of the society. And the person gets stigmatized when being describes by a certain feature, then he gets categorized as being a part of a group that carry the same feature. This leads to losing one's social standard and being discriminated among the surrounding community.

Jack Marten (Jack M., 2017, p. 91) has recently defined stigma as being a negative social phenomenon aiming at diminishing the persons value based on an actual or an imaginary difference in age, gender, sexual interest, social class or race. And the stigma leads to injustice and social abandon.

Stigma is being defined in this current study as the inferior consideration towards any woman whom is known as to be a prostitute, and discrimination towards her, negative expression against her and contempt not only for her, but for her relatives as well and depriving her from some of her rights in the society.

\section{Theories explaining Stigma:}

\section{1) Scheff Theory:}

Scheff's theory (1966) focused upon stigma in the mental field, the applications of this theory has been approved in the field of some diseases. An AIDS patient can be considered as an important event.

\section{2) Dohrenwend, Cullen, Struening \& Shrout's Theory:}

They have offered an updated model of the Stigma Theory, focusing on the social upbringing which is the cause of the development of one's believes about how most people should be treating a stigmatized individual. The more a stigmatized person would have a diminished self-image and feels more discriminated, the more they feel threatened while dealing with others; trying to get educated from situations and the people they believe they reject. (Jolanda S., 2010, p. 212)

\section{3) The Social Theory:}

Al- Kaseer (22:2011) explains that the roots of the Stigma Theory refers back to what (Emale Door Kaim) That many individuals choose moral deviation due to the social impression which has been developed against them as a result of their unacceptable deviated behavior, which remains attached to their social history. 
International Journal of Childhood, Counselling, \& Special Education (CCSE), Volume1, Issue: 1 , September: 2020, pp.11-38

\section{$2^{\text {nd }}$ : Meaning of Prostitution:}

Judith (2014, p27) Still defines prostitution as being sexual connection in return of a paid price. But this term for each of (Eyzenck, Arnold \& Melli) means the relative indifference in the offering of the sexual services (E Dominique Pcolo19, 2012).

Schmitt (2013) and others agreed that prostitution consists of any sexual deeds that are regularly perfomed between individuals of the same or different gender for the sake of a non-humane purpose; in addition to the sexual deeds that are being performed for the sake of gaining money whether they are done between humans, animals or objects, and are being presented to spectators for sexual satisfaction "porn movies" regardless of the presence of emotional respond.

A different definition of prostitution has been mentioned by Cholet and others in their study as being a social problem resulting from selling love from a woman or a young girl to a great number of men in return to the sexual interaction he commits with this woman or young girl.

\section{Definition of a Prostitute:}

(Samya El Saaty) defined the prostitute as for being anyone who takes sexual satisfaction of others of the same or different gender as a job (El Saaty 168: 1983). Except that
Albert Alice defined the prostitute to be anyone who gets involved in a sexual relation, whether it was a man or a woman, even if it has been done for purposes other than the sexual relation itself.

Glades Merry Mole has expanded her definition of prostitutes, as it includes those who are ready to get involved in sexual relations in return of any pleasures, gifts or any other financial benefits and she refers to that to what will be learned as sexual experience which is being chased by people from both genders even if the financial factor hasn't been involved. (Mohammed 26/27: 1984)

\section{Theories Explaining Prostitution:}

\section{The Biological Theory:}

Followers of the biological trend believe that the prostitute has been prepared in advance for this deflected future through a special biological structure that distinguishes her from the others. However, the surrounding cultural and economic situations are only triggers of this structure or alerts for its existence. Hence, the prostitute is defined by some characteristics such as defect in the moral appreciation, nervous and ideological and emotional disturbance, emotional imbalance, carelessness, recklessness, harshness, early tendencies towards vices, indifference of the majorities opinion, weak sense of modesty, an 
International Journal of Childhood, Counselling, \& Special Education (CCSE), Volume1, Issue: 1 , September: 2020, pp.11-38

unlimited sexual desire, the expression of which may take a blatant shameful image. The last point is activation of the sexual and genital glands or the tendency of the body to have sex repeatedly outside the frame of love and marriage. The A person afflicted with the problem of estrus tends to repeat sexual intercourse, not with one person but with many people, which leads the individual to satisfy his sexual and emotional needs through prostitution (Schmitt, 2013, p. 432).

The current researcher disagrees with what has been explaine by the pioneers of the biological theory. It is the religious and moral distinction that guides women, not their biological component. Otherwise, many women would've taken up prostitution because of their sexual cravings, the cruelty of their lives and their emotional disorder. Who among us is not subjected to pressure? Since when is deviation a solution to a problem? Is it logical, for example, to take drugs in order to forget a problem or get out of trouble?!

\section{Economic Theory:}

The economic point of view sees that most prostitutes come from poor families with low economic status, prostitution is a means of gain for women to use to obtain their necessities in case she had no other means of making living. In this case prostitution would be her only way of gaining money which doesn't require any qualifications, education or training. This trend is confirmed by Simon Dévoire, when she indicates that the real causes of prostitution are due to the fact that we are in a world where misery, poverty and unemployment are widespread, leading some females to enter occupations that do not need abilities such as the profession of prostitution. And she adds that a prostitute cannot make a living in another way, society has made prostitution the easiest and most profitable profession since the income from any other profession. Accordingly, great deals of prostitutes are housemaids, since they prefer prostitution to housekeeping. (Allam 1961 : 121)

Acton approaches The same method in interpretation for prostitution according to the economic law, which is the law of supply and demand, as he believes that prostitution nourishes as long as there is high demand for it as a means of satisfying needs. And the demand for prostitution is only an expression of an urgent need that causes this demand. This need is the desire for sexual intercourse, which creates a strong feeling in males during puberty. However, demand is closely related to another aspect, which is supply. Just as demand leads to prostitution, supply in turn creates demand. 
International Journal of Childhood, Counselling, \& Special Education (CCSE), Volume1, Issue: 1 , September: 2020, pp.11-38

The matter is like any other commodity that its abundance of supply and enjoyment of its use increases the demand for it, and the relationship with prostitutes and the enjoying their presence increases the demand for them.

\section{Psychological analysis theory:}

It is seen by the pioneers of the psychological analysis that the prostitution behavior is originated from childhood struggles and defect in the fatherhood love during that stage of one's life particularly, and this shows as aggression against men. The manifestation of this history is shown clearly in the prostitute's preference to revenge from any man ,who is in the same position of the father's image, by offering him sexual satisfaction only without any emotional interaction. Hence, prostitution from the point of view of analyst is developed due to the abundance of the desire of distraction or death over the desire of construction or living, with the control of selfishness and losing the ability of controlling expressions. The disturbance of the building up of the ego, the malfunction of the job that should be performed by the great ego, and the incapability of achieving the compatibility between the different psychological functions also leads to prostitution. (R. Kathleen, 2013).

\section{The Social Theory:}

From the factors encouraging prostitution, as seen by pioneers of the social theory, is imitation and simulation. As when the job is being taken by a number of prostitutes that make money from this job and making their way in the society, a number of men and women imitate them and replicate their deeds and actions. Actions like these, however, drags them into taking up prostitution themselves which eventually leads to increasing the number of prostitutes in the society, and prostitution starts being a threat to the security of the entire society.

Gabriel Tard is considered the first to emphasize the importance of imitation and simulation in the spreading of a certain behavior and transferring it from one place to another or from one group to another. This transfer was named by Tard as "social infection" (Al Hassan 238: 2008)

\section{The Integration Theory:}

The integration theory is well known for its explanation that considers all aspects that are seen by all the previous theories. This theory defines prostitution as a result of biological, psychological, social and economic factors. And the best way to understand the behavior of a prostitute is to analyze her personality based on admitting the importance of the initial groups that 
International Journal of Childhood, Counselling, \& Special Education (CCSE), Volume1, Issue: 1 , September: 2020, pp.11-38

had a great influence on her, the society structure where this process occurs and also admitting the effect of the personal factors. And this is how the complex structure of the personality gets formed.

The individual and the environment are two correlated facts that interact and affect one another. And the functional activity between them leads to achieving stability that dominates the behavior of the individual and his actions. (Al Saaty 199 - 200: 1984)

Finally, it is important to point out that the existence of these factors does not necessary lead to taking up prostitution; and the presence of females whom to which some, or all, of these factors are applicable but didn't end up to be prostitutes is the proof. The responding to these factors and not to their presence is what leads to taking that rout. (Al Reedy 398 - 399: 2003)

\section{The Psychodynamic Theory:}

(M. Itai and S.M. Kang) assure that prostitution a special dynamic. Three causes lead to it:

- Economic resources which causes increase of the appearance of unbalanced families.

- cultural attrition

- increase in the moral decadence

And most of the studies in this area assured the presence of the social factors which lead to prostitution. The Psychodynamic theory also explains that some cultures have negative static patterns towards the prostitute by stigmatizing her with some labels that never parts her; e.g. whore or bitch. (Monica R, et al, 132. 2016)

\section{Previous Studies:}

After reviewing psychological literature, scientific researches in this field, and collecting many Arab or foreign researches and studies that helps the researcher in his current study, he classified these researches into two groups:

- The First Group: specializes with studies that explained the Stigma

- The Second Group : specializes with studies that explains Prostitution

\section{First: Studies that explained Stigma}

Mond's study was one of the first studies explaining Stigma (Mond and Robertson, 2006) and it wa s entitled "Stigma and eating disorders".

The study sample consisted of 250 woman. The researcher used several tools including a scale to assess the level of selfishness, psychological eating disorder and Stigma scale. The study showed the following results:

Stigma through movies and television is less negative, while other 
International Journal of Childhood, Counselling, \& Special Education (CCSE), Volume1, Issue: 1 , September: 2020, pp.11-38

types of Stigma has little to nonexistent effects among women.

Then comes Nermin Abu Spetan's Study 2014 entitled " Social Support and Stigma and the relation with psychological strengths and acceptance of life for divorced women in Ghaza ". Study sample consisted of 281 divorced women; the researcher used the following tools:

- Social support survey

- Stigma survey

- Psychological stability survey

- Level of life acceptance survey

The study reached to the following results:

- The presence of an inverse relation with statistical reference between Stigma and the overall social support and the support offered from family, relatives and friends of the divorced women.

- The presence of an inverse relation with statistical reference between Stigma and the psychological strength and its effects on divorced women.

- The absence of fundamental differences with statistical references in the levels of Stigma and the social support and psychological strength and life acceptance for divorced women due to the variables in the region, number of children, the difference in the Stigma

- The presence of fundamental differences with statistical references in the levels of Stigma and the social support and psychological strength and life acceptance for divorced women due to the scientific degree

- The presence of fundamental differences with statistic reference in the levels of Stigma and life acceptance for divorced women due to the family type.

(Sydney .H \& Kinnear, B. G, 2016) study aimed to acknowledge the effect of the stigma on the lives of autistic children's families. And this is based on a sample of (455) families in the United States and Canada, it concluded that the stigma increases the difficulty of raising children who suffer from autism. Never the less, the stigma plays an important role in socially rejecting autistic kids. Finally, the study concluded that stigma plays an important role in the prediction of difficulty in all life aspects for the families of autistic kids.

In the same context of the previous study, Marwa Abu Lifa's (2017) study was on stigma and its relation with the psychological and social problems of mothers of autistic children in the Gaza, where the study sample consisted of (140) mothers of autistic children. The 
International Journal of Childhood, Counselling, \& Special Education (CCSE), Volume1, Issue: 1 , September: 2020, pp.11-38

researcher used the stigma scale, and a measure of psychological and social problems. The study concluded several results: The stigma ratio was average for the study sample, and there was a relationship between stigma and psychological and social problems.

Finally, in a study made by both (Joan M. \&Alana, 2019) aimed at recognizing the factor of attraction in prostitution. The sample consisted of 14 of the participants (prostitutes) whom have been frequently exposed to the court of prostitution and 8 pimps. The researchers used a tool to recognize the possibility of the presence of a desire to repent and the role of pimps in prostitution. The study concluded that there are three types of stigma: physical stigma, general stigma, and personal stigma. The research also concluded that these courts are useless in the absence of security and social efforts, the internal desire from the prostitutes themselves and limiting the role of pimps. Finally, the study presented a proposal for the necessity of social services and special care for these repentant women.

\section{Second: Studies related to prostitution:}

The first of these studies is the study of Ihsan Al-Hassan (2008), on prostitution and brokering, the causes and treatments, "a social field study", through which the goal was to diagnose the objective and subjective causes of prostitution. The sample of the study consisted of (67) women, where the researcher designed a questionnaire consisting of 20 questions, as used in the interview. The results of the study concluded that weak values, morals, and poor socialization are among the most important causes of prostitution. Never the less, economic factors have had a role in women's prostitution such as (poverty, impotent conditions for marriage, desire to diversify of experiences, imitation and simulation).

In Manal Abo Derbala's study (2013) that was titled "body image for women engaged in prostitution", the sample consisted of 3 females with ages ranging from 26 to 32 and all highly educated. The study tools consist of: interview, observation, core analysis. The study concluded that all the participants do not have the feeling of possession of their bodies and losing the body value. The study also emphasized that the cases have a feeling of physical beauty, in addition to strong insistence on proceeding in prostitution.

In an important study for (Anna, Manduic, 2014) aimed to explain the effect of the prostitute mother on the life of her children. The sample consisted of 5 mothers who work in sex, married and have children. The researcher used the life scale with a 
International Journal of Childhood, Counselling, \& Special Education (CCSE), Volume1, Issue: 1 , September: 2020, pp.11-38

prostitute mother. She also depended in her results on analyzing the interviews and concluded several results, and most important were: prostitution has negative effects on carrying responsibilities of the mother like caring, attention and warmth. It also affects the education of the kids negatively as some of the mothers were imprisoned as a result of working in prostitution. Finally, the study proved that psychological health for those kids is bad and suffers from dangerous psychological disorders.

Finally (Aaron Muman et al, 2017) and others accomplished their studies which aimed to find out the effect of family therapy based on the work environment with drug addicts and prostitutes. The study sample consisted of (66) drug addict women prostitutes. The tools used:

Family therapy program which consists of 12 sessions is applied individually is considered as a social family relations scale. The study concluded several results from which: most of the prostitute women demand a cure from drug addiction. The results also showed that the women who have taken family therapy showed a clear decrease in the level of drug addiction and depression symptoms. Plus, better improvement in the mother child interaction. The results prove the importance of offering family therapy as an option of a cure when prostitutes who have children ask for a cure from drug addiction.

\section{Comment on the previous studies:}

Stigma studies were exposed to the subject through stigma of appearance and behavior (Mond et al, 2006 and others). Their study sample was women with eating disorders, and others linked psychological disorders, divorce, and stigma (Abo Sbetan, 2014). (Sindy Wekinearer, 2016), and recently (Abo Lifa, 2017).

Other studies have confirmed the presence of factors attracting to work in prostitution (Joan M. \& Alana study, 2019). Then comes studies of prostitution, which examine prostitutes from more than one angle: either that prostitution is a business and a job (Al Hassan, 2008) or the body vision to the prostitute (Abo Derbala 2013).

Then comes the study that with features approaching the current study, which is the study of (Anna Mandiuc, 2014) which concluded the dangers of the prostitute mother over the social and psychological lives of her children.

There are also studies that have linked prostitution with drug addiction (Aaron. Et al, 2017). 
International Journal of Childhood, Counselling, \& Special Education (CCSE), Volume1, Issue: 1, September: 2020, pp.11-38

\section{Hypotheses of the study:}

1) The scale prepared in the current study is valid for revealing stigma for adolescents of prostitute mothers.

2) The variation in the order of the dimensions of stigma anxiety among adolescents of prostitute mothers.

3) There are significant differences in stigma anxiety among adolescents of prostitutes' mothers based on the gender (male and female)

4) There are significant differences in stigma anxiety among adolescents of prostituted mothers due to the place of residence (rural and urban).

\section{Study Methodology and Procedures:}

\section{First: Study Methodology:}

The researcher has adopted the relational descriptive approach because it is the appropriate approach to study the problem of this study. Since the study is aiming at describing phenomena and events, collecting facts and information, making observations, describing the special conditions and determining their status as they exist in reality and expressing them in terms of quantity and quality.

\section{Second: The Study Sample:}

The current study sample included 28 adolescents (males and females).

Table 1. Demographic variables for the study sample

\begin{tabular}{lccc}
\hline Demographic Variables & & number & Percentage \\
\hline \multirow{2}{*}{ Gender } & Male & 19 & $67.9 \%$ \\
& Female & 9 & $32.1 \%$ \\
Age & Above 20 & 20 & $71.4 \%$ \\
\multirow{2}{*}{ Area of residence } & From 13- 19 & 8 & $28.6 \%$ \\
Number & Rural & 10 & $35.7 \%$ \\
& Urban & 18 & $64.3 \%$ \\
\hline
\end{tabular}

Distribution of the sample members in a moderate distribution:

the individuals of the various samples under investigation related
The researcher confirmed the level of the moderation of distribution of

to the stigma anxiety scale, and Table (2) illustrates this. 
International Journal of Childhood, Counselling, \& Special Education (CCSE), Volume1, Issue: 1 , September: 2020, pp.11-38

Table 2. Mean, median, standard deviation and coefficient of torsion For the sample under consideration in the Stigma Anxiety Scale $(n=28)$

\begin{tabular}{lllll}
\hline Scale & mean & median & $\begin{array}{l}\text { Standard } \\
\text { deviation }\end{array}$ & Coefficient of torsion \\
\hline Social stigma & 49.25 & 49 & 2.32 & 0.32 \\
Psychological stigma & 41.96 & 42 & 1.43 & -0.08 \\
Personal stigma & 36.71 & 37 & 2.21 & -0.39 \\
Chasing or future stigma & 26.71 & 26.5 & 2.31 & 0.28 \\
Total grade & 154.64 & 155 & 6.93 & -0.15 \\
\hline
\end{tabular}

It is clear from table 2 that the coefficient of torsion for the sample that's being studied for the stigma anxiety scale ranged between $(-0.39$, 0.32) which means that it was between $(-3,+3)$ which showed that it lies within the normal distribution curve, which shows that the sample has been distributed normally.

\section{Third: Study tools}

Scale construction procedures:

There are special scientific steps for building psychological scales. Which start with identifying the theoretical concepts to which the researcher has referred in constructing the scale. (Cornbach, 1970. p530) pointed to the importance of starting by identifying the building concepts to which construction of psychological scale process refers before starting the construction process.

1. Specifying the feature that has to be measured: in this study it is stigma.

2. Specifying the aim of the scale: the aim is studying the symptoms of Stigma anxiety for adolescents of prostitute mothers.

3. Analyzing the feature to the dimensions that represent it, and these dimensions were represented as: psychological Stigma, social stigma, personal stigma, chasing or future stigma.

Theoretical and methodological premises for building scale: its undeniable that any research tool must have a reference that justifies its construction and application. The researcher has revised the available theoretical studies despite their minority. The methodology and concepts, that the researcher is referring to, have been identified for confirming the procedures for constructing the scale. Accordingly, the researcher set the following theoretical concepts:

The researcher depended on the self-report style (affirmative statements) in building up the blocks of the scale.

Stigma anxiety scale is considered a whole unit that can be measured, as the concept of stigma 
International Journal of Childhood, Counselling, \& Special Education (CCSE), Volume1, Issue: 1 , September: 2020, pp.11-38

anxiety is a group of behaviors and correlated interactions that usually occur together.

Identifying the concept of stigma anxiety: after defining stigma anxiety, the researcher set the behavioral components and the dimensions of this concept based on the theoretical frame for the current research which are 4 components of stigmatizing, explained in 36 blocks

Formulating scale statements: based on the previous steps the researcher framed the scale statements

Scale instructions and ways of editing: the scale is aiming at teenagers, as they reply to the scale statements by crossing (X) the statement he finds applicable to himself. (always applies 5 - applies 4 - sometimes applies 3 - doesn't apply 2 - never applies 1 )

Identifying the subject of the scale and the formation of its sections: (provided by the researcher in person)

Forming the initial version of the scale and judging it: after forming the scale in its initial version which is formed from 36 blocks, he stressed on the stigma for those teenagers then presenting it to a jury of specialized psychiatrist and psychology health experts and the proper adjustments have been made according to their instructions. The scale kept its blocks after the linguistics and formal adjustments. Accordingly, the total sum of the tool ranged between 36 to 180 degrees.

The psychometric properties of the scale:

The researcher calculated the psychometric properties of the scale as follows:

First: validity of the scale:

To confirm the validity of the scale the researcher calculated the level of validity in two ways, content validity, factor validity and the internal consistency validity, as follows:

Content validity:

The researcher presented the scale in its initial version to a jury of specialized psychiatrist and psychology health experts and family consultants made of 10 experts and that's to express their opinion and alignment of the scale with the aim it has been made for. The percentage of the expert's opinions ranged between (80 - $100 \%)$ accordingly, the statements have been approved for taking higher than $70 \%$ of the approval so the final version consists of 36 blocks.

Factor validity:

The factor analysis took place in the form of principal components. It produced 4 factors and Guilford structure of intellect theory $(0.3)$ was 
International Journal of Childhood, Counselling, \& Special Education (CCSE), Volume1, Issue: 1 , September: 2020, pp.11-38

used for selecting the function factor loading, the statements that are saturated on more than one factor with values that are not close have been chosen, and the factors upon which three or more statements with a value of factor loading of $(0.3)$ have been saturated or chosen. And statements that scored factor loading less than (0.3) have been canceled to ensure better factor purity for the factors. Follows is the description of these factors.

Table 4. Factor loading for the first factor

\begin{tabular}{|c|c|c|}
\hline $\begin{array}{l}\text { Number of } \\
\text { statements }\end{array}$ & Statement & Factor loading \\
\hline 28 & I get humiliated and insulted due to my mother's reputation & 0.932 \\
\hline 5 & People treat me differently because of my mother & 0.915 \\
\hline 1 & $\begin{array}{l}\text { I feel that my friends are not dealing with me because of my mother's } \\
\text { behaviors }\end{array}$ & 0.879 \\
\hline 2 & $\begin{array}{l}\text { I don't get invited to participate in gatherings and occasions from my } \\
\text { relatives and acquaintances. }\end{array}$ & 0.867 \\
\hline 4 & $\begin{array}{l}\text { I get bothered by other's sympathy due to the rumors around my } \\
\text { mother }\end{array}$ & 0.866 \\
\hline 10 & I get humiliated due to the roomers spreading about my mother & 0.861 \\
\hline 34 & I wish I could die to rest from the chasing of bad reputation & 0.854 \\
\hline 3 & $\begin{array}{l}\text { I stay away from social situations and I have no desire to interact with } \\
\text { people especially whom I know }\end{array}$ & 0.851 \\
\hline 12 & $\begin{array}{l}\text { When I meet someone for the first time, I try hard to hide what spreads } \\
\text { about my mother }\end{array}$ & 0.843 \\
\hline 6 & My friends treat me with disrespect because of my mother & 0.75 \\
\hline $\begin{array}{c}31 \\
(23.99 \%) \mathrm{Eig}\end{array}$ & $\begin{array}{l}\text { I'm seriously considering immigration } \\
\text { value (8.64) and variance }\end{array}$ & 0.748 \\
\hline
\end{tabular}

From the previous table, it is clear that the Eigenvalue for that factor reached (8.64), the factor variance $(23.99 \%)$ and the factor loading with this factor is (11) words. For that, the researcher suggested naming this factor "psychological stigma".

Table 5. Factor loading for the second factor

\begin{tabular}{clc}
\hline $\begin{array}{c}\text { Statement } \\
\text { number }\end{array}$ & \multicolumn{1}{c}{ The Statement } & factor loading \\
\hline 17 & $\begin{array}{l}\text { I felt the negativity of surrounding situations towards my mother's } \\
\text { problems }\end{array}$ & 0.91 \\
15 & My mother is the reason of my feeling of injustice and oppression & 0.905 \\
26 & I want to change my place of residence because of how people look at me & 0.903 \\
36 & $\begin{array}{l}\text { I feel great hatred towards myself } \\
22\end{array}$ & $\begin{array}{l}\text { My neighbors look at me in a suspicious way } \\
\text { I feel an inferior look from my friends and relatives because of my }\end{array}$ \\
19 & $\begin{array}{l}\text { mother's behaviors } \\
\text { I notice unwillingness of others to talk to me from those who know my }\end{array}$ & 0.897 \\
\hline
\end{tabular}


International Journal of Childhood, Counselling, \& Special Education (CCSE), Volume1, Issue: 1 , September: 2020, pp.11-38

\begin{tabular}{clc}
\hline 21 & Other reject proceeding talking to me when they who my mother is & 0.804 \\
24 & I face difficulty in making new friends & 0.804 \\
(23.97\%) Eigenvalue (8.63) and variance & \\
\hline
\end{tabular}

From the previous table, it is loading with this factor is (9) words. clear that the Eigen value for that factor reached (8.63), the factor For that, the researcher suggested variance $(23.97 \%)$ and the factor

naming this factor "social stigma"

Table 6. Factor loading for the third factor

\begin{tabular}{clc}
\hline $\begin{array}{c}\text { Statement } \\
\text { number }\end{array}$ & \multicolumn{1}{c}{ Statement } & factor loading \\
\hline 11 & I fail at expressing my point of view easily & 0.948 \\
9 & I feel the desire of parting from others towards me & 0.942 \\
13 & There are people who call me "son of the woman that has bad & 0.889 \\
16 & reputation" and humiliate me with it. & 0.854 \\
35 & I tried repeatedly to help my mom stay away from her path & 0.825 \\
20 & I feel that my presence has become a burden for those who & 0.684 \\
8 & surround my & 0.666 \\
32 & I feel not welcome at my relatives and acquaintances & 0.647 \\
7 & I feel that my mother dies & 0.614 \\
\hline
\end{tabular}

From the previous table, it is clear that the Eigen value for that factor reached (6.67), the factor variance $(18.52 \%)$ and the factor loading with this factor is (9) words. For that, the researcher suggested naming this factor "personal stigma"

Table 7. Factor loading for the fourth factor

\begin{tabular}{|c|c|c|}
\hline $\begin{array}{l}\text { Statement } \\
\text { number }\end{array}$ & Statement & Factor loading \\
\hline 25 & $\begin{array}{l}\text { I expect that I'll face difficulties in marriage due to my mother's } \\
\text { reputation }\end{array}$ & 0.881 \\
\hline 30 & The others' negative look hurts me & 0.875 \\
\hline 33 & $\begin{array}{l}\text { My mother's reputation affected how my siblings were raised } \\
\text { negatively }\end{array}$ & 0.812 \\
\hline 18 & Little number of friends visit me & 0.809 \\
\hline 23 & I get the feeling that my acquaintances talk behind my back & 0.713 \\
\hline 29 & I feel ashamed of my mother's reputation & 0.699 \\
\hline $\begin{array}{c}27 \\
(13.83 \%) \mathrm{E}\end{array}$ & $\begin{array}{l}\text { My enjoyment of regular life activities like clubs and occasions is very } \\
\text { little because of my mother } \\
\text { envalue (4.98) and variance }\end{array}$ & 0.648 \\
\hline
\end{tabular}


International Journal of Childhood, Counselling, \& Special Education (CCSE), Volume1, Issue: 1, September: 2020, pp.11-38

From the previous table, it is clear that the Eigen value for that factor reached (4.98), the factor variance $(13.83 \%)$ and the factor loading with this factor is (7) words. For that, the researcher suggested naming this factor "chasing and future stigma"

From what the researcher has discovered through the factor analysis, the scale's dimensions were created as follows:

Table 8. Stigma anxiety Scale dimensions and its statements after the factor analysis

\begin{tabular}{|c|c|c|}
\hline Dimension & $\begin{array}{l}\text { Number of } \\
\text { statements }\end{array}$ & Statements numbers \\
\hline Social stigma & 11 & $1 / 2 / 3 / 4 / 5 / 6 / 10 / 12 / 28 / 31 / 34$ \\
\hline Psychological stigma & 9 & $14 / 15 / 17 / 19 / 21 / 22 / 24 / 26 / 36$ \\
\hline Personal stigma & 9 & $7 / 8 / 9 / 11 / 13 / 16 / 20 / 32 / 35$ \\
\hline $\begin{array}{l}\text { Chasing and future } \\
\text { stigma }\end{array}$ & 7 & $18 / 23 / 25 / 27 / 29 / 30 / 33$ \\
\hline Total & 36 & \\
\hline
\end{tabular}

Validity of the internal consistency:

To calculate the validity of the internal consistency of the scale, the researcher applied it to a sample of (40) individuals from the research community and not the original sample of the research. Correlation coefficients ranged between the degree of each phrase and the total degree of the dimension belonging to it between (0.70: 0.95). Correlation coefficients ranged between the score of each phrase and the total score of the scale between (0.45: 0.75), and correlation coefficients ranged between the sum of the scores of each dimension and the overall score of the scale between (0.63: 0.76) which are statistically significant correlation coefficients which indicates internal consistency for the scale.
Stability:

To calculate the stability of the scale, the researcher used the following methods:

(1) Alpha coefficient of Cronbach:

To calculate the stability of the scale, the researcher used the Alpha coefficient of Cronbach by applying it to a sample of (40) individuals from the research community and outside the original sample, and alpha coefficients for the dimensions of the scale ranged between (0.91: 0.96), as the coefficient reached Alpha of the scale (0.96), which are statistically significant correlation coefficients, which indicates the stability of the scale.

(2) Split-half reliability method:

To calculate the stability of the scale, the researcher used the splithalf reliability method by dividing 
International Journal of Childhood, Counselling, \& Special Education (CCSE), Volume1, Issue: 1 , September: 2020, pp.11-38

the scale into two equal parts , individual phrases versus even phrases, then the correlation coefficient between them was calculated by applying them to a sample of (40) individuals, and after calculating a correlation coefficient, the researcher applied the Spearman and Brown equation to find the coefficient of stability, and the correlation coefficient between the degrees of odd and even terms of the scale (0.57), the coefficient of stability (0.73), which are statistically significant correlation coefficients, which indicates the stability of the scale.

\section{The Results:}

First: Verification of the validity of the first hypothesis, which states that: The scale prepared in the current study is suitable for detecting anxiety stigmatization among adolescents of prostitute mothers. In order to verify this hypothesis, the researcher used the factor analysis and the results of validity and consistency, which showed the ability of the scale to measure stigma anxiety among adolescents of mothers with a goal where the factors of validity and consistency scored high degrees, and the results of the factor analysis also revealed that there are four sub-dimensions of the scale made up of the phrases (36) The concern of stigma is represented by:
1) Social Stigma: The current researcher defines it as "the social reaction towards stigmatized persons and the accompanying negative attitudes and attitudes towards them from members of society, groups, and official institutions, expressing denunciation, mockery, rejection, social rejection for them and their families in particular, which imposes on them a kind of social isolation."

2) Psychological stigma: is the negative expectation by the stigma - from society and its individuals - in dealing with it, this expectation falls within the framework of the word defect (negative stereotype)

3) Personal Stigma: It is the feeling of the person stigmatized (or his relatives and in our current study the stigma is the son / daughter of the prostitute) of shame and humiliation as a result of his actions or the actions of one of his relatives that the community and its individuals and institutions reject. Stigma stems from personal perceptions of stigma when individuals rely on negative assumptions about themselves

4) The future stigma: It means the stigmatized fear, or his relatives, of lack of feasibility even after repenting and of being disgraced 
International Journal of Childhood, Counselling, \& Special Education (CCSE), Volume1, Issue: 1, September: 2020, pp.11-38

by society in his individuals and law.

Second: To verify the validity of the second hypothesis, this state: The order of the dimensions of stigma anxiety among adolescents of prostitute mothers varies. To validate this hypothesis, the researcher extracted the averages for the dimensions of the stigma anxiety scale as shown in the following table:

Table 9. The mean and percentage of research sample scores on stigma anxiety scale $(n=28)$

\begin{tabular}{llll}
\hline Dimensions & Mean & Percentage & Order \\
\hline Social stigma & 49.25 & $89.55 \%$ & 2 \\
Psychological stigma & 41.96 & $93.25 \%$ & 1 \\
Personal stigma & 36.71 & $81.59 \%$ & 3 \\
Future stigma & 26.71 & $76.33 \%$ & 4 \\
Total & 154.64 & $85.91 \%$ & \\
\hline
\end{tabular}

It is clear from Table (9) that the percentage of research sample scores on the stigma anxiety scale ranged between (76.33\%: 93.25\%), as it came in the first order (psychological stigma), and in the second order (social stigma), also came in the third order (Personal stigma), and finally (future stigma) came in the fourth and final order

In this regard, the current researcher sees the logic of the result, and even the types of stigmatization interconnected in order, and since the current sample of adolescents of prostitute mothers. Then the situation became critical for several considerations, including the important and dangerous age to which the study sample belongs is that of adolescence, including stress, anxiety, and love of self-affirmation and showing it in the best and strongest form. All of this comes as a total disgrace, the mother is notorious and everyone knows.
Here comes the second consideration, the great contradiction between the teenager's aspirations and dreams, and the humiliating reality of his mother and the feeling of inferiority and degradation. All this marks the psychological stigma. . Then comes the feeling of social stigma, where the teenager goes out of his house to meet the looks of others, whispering and frankly pursuing and sometimes even confrontation. So, the teenager finds himself an are desired. Then comes the feeling of personal stigma, and here some may be surprised by the delay in the appearance of the personal stigma at the teenager, as it is from their point of view that it is supposed to be the first stigma to appear.

Here, the current researcher sees that the psychological stigma is not separated from the personal stigma. In fact, the teenager's sense of the stigma undoubtedly suffers from a 
International Journal of Childhood, Counselling, \& Special Education (CCSE), Volume1, Issue: 1 , September: 2020, pp.11-38

parallel feeling of the personal stigma. This confusion and surprise afflict the teenager with negative feelings mixed between feeling shame and shame, and wishing death to the mother or to his own self sometimes.

Finally, the stigma of the future disgrace comes and the current researcher believes that its arrangement is logical, as the teenager at the end of his tragedy looks at the dark tomorrow. Is changing the place enough to end the suffering and shut up the tongues?

Does the mother stop what she does, even for years, to prevent the harsh gossip and silent the chatter inside the mouths and minds of those who know neighbors and others? Here, a question asked by Cecilia, et al, 2017 comes to mind. Are all the families of the prostitutes unhappy with their work?

The researcher answers that the difference and the moral gap between foreign societies and our Arab societies is very large. Prostitution remains an ethical crime forbidden by all religions, and the prostitute woman is still socially rejected and behaviorally reprehensible.

This is partly consistent with what (Lawrence $H, 2007$ ) states that the concept of stigma is "two-sided" as it is a concept with an ethical / physical dimension, as it relates to physical experience, and another ethical / emotional dimension, associated with emotional experience.

Third: To verify the validity of the third hypothesis, which states: There are fundamental differences in stigma anxiety among adolescents of prostitutes mothers due to the gender (male or female). To verify the validity of this hypothesis, the researcher extracted the significance of the differences between the genders in the dimensions of the stigma anxiety scale, as shown in the following table.

Table 10. Significance of male and female differences in adolescent stigma anxiety among prostitute

\begin{tabular}{llllllll}
\multicolumn{7}{c}{ mothers $(n=28)$} \\
Scale & Males & \multicolumn{3}{c}{ females } & Value of \\
\cline { 2 - 5 } & Mean & $\begin{array}{l}\text { Standard } \\
\text { deviation }\end{array}$ & mean & $\begin{array}{l}\text { Standard } \\
\text { deviation }\end{array}$ & $\begin{array}{l}\text { Level } \\
\text { significance }\end{array}$ & of \\
Social stigma & 49.63 & 2.59 & 48.44 & 1.42 & 1.28 & No significance \\
$\begin{array}{l}\text { Psychological } \\
\text { stigma }\end{array}$ & 42.11 & 1.7 & 41.67 & 0.5 & 0.75 & No significance \\
Personal stigma & 36.47 & 2.39 & 37.22 & 1.79 & 0.83 & No significance \\
Future stigma & 26.89 & 2.6 & 26.33 & 1.58 & 0.59 & No significance \\
Total & 155.11 & 8.08 & 153.67 & 3.67 & 0.51 & No significance \\
\hline
\end{tabular}

The value of the tabular $(\mathrm{T})$ at the level $(0.05)=2.06(0.01)=2.78 *$ Significant at the level $(0.05){ }^{* *}$ significant at the level (0.01) 
International Journal of Childhood, Counselling, \& Special Education (CCSE), Volume1, Issue: 1, September: 2020, pp.11-38

It is clear from Table (10) that there are statistically significant differences between males and females in the stigma anxiety of adolescent of prostitute mothers.

The current researcher points to the logic of the previous result, as disgrace has a shocking effect that we find equal for both male and female adolescents. The male teenager has a future job and marriage to worry about and the female teenager is looking for a husband, stability and job. How can they make wishes with all the shame and stigma chasing them as the children of a notorious prostitute? It is easy to get a job, husband or wife; but what is the guarantee that the mother's image, reputation, action and behavior wouldn't jump in front of him or her with the first disagreement or difference in points of view? Even if this would not be explicitly revealed to the other side, the latter will read it in his or her eyes or hear it in the tone of his or her voice.

This finding is partly consistent with the results of the study of (Joseph D. Wollmana et al. et al, 2019) which confirmed that the stigma of being overweight does not differ between males and females in the United States. Also, with the result of the Lisa Townsend study, 2019, whose results have showed in equal feeling of stigma between males and females in mental illness, especially depression, although females are more affected by the disease and males are more likely to commit suicide than females.

Finally, the results of the foreign study, which was conducted in Abu Dhabi, United Arab Emirates, by a large group of researchers headed by (Nicoline Schiess, et al 2019). The study concluded that the stigma of mental illness (anxiety and depression) does not differentiate between male and female as they are similar in feelings of stigma and shame as a result of their mental illness.

Based on the above, the current researcher confirms that we are dealing with a more serious and deeper problem than mental illness or obesity. Prostitution, like wildfire, does not focus stigma and shame on the owner of the same behavior "the mother" but extends to all members of her family, especially children, whether she is divorced or a widow. Here, we will not find clear differences between feelings of stigma of shame and the sense of inferiority between male and female adolescents belonging to a prostitute mother.

Fourth: Verifying the validity of the fourth hypothesis, which states: There are significant differences in stigma anxiety among adolescents of prostituted mothers due to the place of residence (rural, urban). To verify the validity of this hypothesis, the researcher extracted averages and 
International Journal of Childhood, Counselling, \& Special Education (CCSE), Volume1, Issue: 1, September: 2020, pp.11-38

standard deviations for the dimensions of stigma anxiety scale as shown in the following table:

Table 11. Significance of the differences between rural and urban in stigma anxiety among adolescent of prostitute mothers $(n=28)$

\begin{tabular}{|c|c|c|c|c|c|c|}
\hline \multirow[b]{2}{*}{ Scale } & \multicolumn{2}{|l|}{ Rural } & \multicolumn{2}{|l|}{ urban } & \multirow{2}{*}{$\begin{array}{l}\text { Value of } \\
T\end{array}$} & \multirow{2}{*}{$\begin{array}{l}\text { Level of } \\
\text { significance }\end{array}$} \\
\hline & mean & $\begin{array}{l}\text { Standard } \\
\text { deviation }\end{array}$ & Mean & $\begin{array}{l}\text { Standard } \\
\text { deviation }\end{array}$ & & \\
\hline Social stigma & 51.3 & 1.83 & 48.11 & 1.71 & $4.61^{* *}$ & 0.01 \\
\hline $\begin{array}{l}\text { Psychological } \\
\text { stigma }\end{array}$ & 43.1 & 0.88 & 41.33 & 1.28 & $3.87^{* *}$ & 0.01 \\
\hline Personal stigma & 38.1 & 1.37 & 35.94 & 2.24 & $2.76^{*}$ & 0.05 \\
\hline Future stigma & 28.4 & 2.22 & 25.78 & 1.8 & $3.40^{* *}$ & 0.01 \\
\hline Total & 160.9 & 4.89 & 151.17 & 5.27 & $4.80^{* *}$ & 0.01 \\
\hline
\end{tabular}

The value of the tabular $(\mathrm{T})$ at the level $(0.05)=2.06(0.01)=2.78{ }^{*}$ Significant at the level $(0.05){ }^{* *}$ significant at the level (0.01)

From Table (11) it is clear that there are statistically significant differences between rural and urban in stigma anxiety among adolescent of prostitute mothers and in favor of rural.

In this regard, Monica explains through her study of culture and her disagreement with the way of dealing with the phenomenon of prostitution that there are some cultures that develop negative stereotypes towards prostitutes by stigmatizing them with some names they do not separate, such as: prostitute, bitch or whore. These cultures are the cultures of coherent social environments and extended families

(Monica R, et al, 2016, 132). What Monica explained is not awkward as within the rural environment and what it contains from very close social classes, the close families that all know one another and the similarity in their habits and traditions, All of these factors make the subject of prostitution something that cannot be hidden nor accepted, but it must be fought with all its sides equally, woman or family.

The situation may reach the attempt of expulsion of that family from the village in order to ward off the shame. Not to mention the upper Egypt culture and its contents of words; like insult, shame and scandal; only when a woman puts on inappropriate clothing or talking in a way that is considered crossing the boarders of decency and respect. However, a prostitute could get killed by those who live in this conserved environment. But speaking of stigma, it will chase her family and relatives whether she was dead or alive. So the result of the 
International Journal of Childhood, Counselling, \& Special Education (CCSE), Volume1, Issue: 1 , September: 2020, pp.11-38

previous imposition in favor of rural teenagers was a rise in anxiety.

Perhaps one of the main reasons for the prevalence of prostitution in rural society is the weak awareness and general knowledge and low moral and religious impulses, especially with ease of seduction through modern means of communication in today's world, such as the internet, mobile phones, and others.

On the other hand, western societies allow prostitution under the umbrella of freedom, while increasing restrictions on marriage and polygamy and imposing laws to restrict laws God's law. These practices are not considered as a detriment to the woman's humanity in the western societies as it counts as a part of her freedom, progress, dignity and her role in life. And it is more surprising that some of our eastern societies started to devote to this idea and allow it.

From the results of the study, it can be concluded that the stigma anxiety measure of adolescent of prostitute mothers was reached.

The conclusion of the study, in which:

Recommendations:

1) Take advantage of the current research tool in future researches.
2) Working on increasing the health awareness of women in general and of prostitutes in particular regarding the health and social risks of this behavior.

3) Work to increase the activation of the oversight role (security, family) to try to limit the spread of this phenomenon.

4) The need for a repentant woman to have another chance, especially from her family and relatives, and then from society.

5) Forming what is called the Support Group, which is a group of people specializing in psychology, sociology, and psychiatry, medicine and other related fields. The goal of this group is to help the stigmatized women by relieving them and take their hands and aid them not to return to this path despite any the challenges or temptations. In the current research we launch this initiative which is the formation of a support group for repentant women (ISGRW).

The proposals:

1) Conducting a study on "the husband's disability (sexual, financial, and emotional) and its relationship to wife prostitution". 
International Journal of Childhood, Counselling, \& Special Education (CCSE), Volume1, Issue: 1, September: 2020, pp.11-38

2) Conducting a study to clarify "the differences between a married and unmarried prostitute".

3) Conducting a study on "the psychological structure (psychological anatomy) of a prostitute woman"

\section{References}

Aaron Murnan \& Qiong Wu, Natasha Slesnic (2017). Effects of Ecologically Based Family Therapy with substance using, prostituting mothers. Journal of Family therapy. 32(2), pp. 339-3564.

Abu Aspetan, Nermin Suleiman (2014). Social support and stigma and their relationship with psychological hardship and satisfaction with life for divorced women in Gaza Governorate. An unpublished master's thesis. Islamic University of Gaza.

Abu Lifa, Marwa Nahed (2017). Stigma and its relationship with the psychological and social problems of mothers of autistic children in the Gaza. An unpublished master's thesis. Faculty of Education, Islamic University of Gaza

Acton.w (1968). Prostitution, edited by peter fryer, London. Macg ibban \& kee.

Al-Hassan, Ehsan Muhammad (2008). Sociology of crime. Amman: Wael Publisher.

Allam, Hasan (1961). Social factors in the phenomenon of professional prostitution, publications of the National Center for Social and Criminal Research, works of the first cycle to combat crime. Cairo

Al-Quasir, Bandar Salem (2011). Manifestations of Social Stigma from the Attachment of Social Welfare Home,
Master's Thesis. Unpublished. Prince Naif Arab University for Security Sciences. Riyadh

Al-Reedy, Muhammad (2003). Social factors related to female crimes in Saudi society an applied study on the Saudi female detainees in the prison of Riyadh, Jeddah, Dammam, Al-Ahsa and all institutions for girls care in the Kingdom of Saudi Arabia, Master's Thesis. Unpublished. Prince Naif Arab University for Security Sciences. Riyadh.

Ana. Maria Mandiuc. (2014). The impact of a prostitute mother on the child life circumstances. European Journal of Research on Education, 2(2), 1-9. https://doi.org/10.15527/ejre.201426243

Bouderbala, Manal Mohamed (2013). Body image of women practicing prostitution, field study, Setif Province, Ph.D., unpublished. Faculty of Humanities and Social Sciences, University of M'sila. Algeria.

Cecilia Benoit, Michaela Smith, \& Mikael Jansson (2017). Sex work and three dimensions of self-esteem: self-worth, authenticity and self-efficacy. Journal for Research, Intervention and Care, V (20), pp 69-83.

Cho, S., Dreher, A., Neumayer, E. (2013), Does Legalized Prostitution Increase Human Trafficking? World, Development. European Journal of Law \&Economics, 35 (1), 87-107.

Cronbach, J.H. (1970): Essentials of Psychological testing, 2ed, New York .Harper and Rublishers.

Dominique E \& Roe. Sepowitz (2012). Juvenile Entry into Prostitution "The Role of Emotional Abuse", Journal of Trauma and Dissociation, 8, 7-26 . 
International Journal of Childhood, Counselling, \& Special Education (CCSE), Volume1, Issue: 1, September: 2020, pp.11-38

Faraj, Safwat (1980). Psychometrics, 1st stage. Cairo: Dar Al-Fikr Al-Arabi.

Ghalem, Yamina, Maysum, Laili (2017). Building a Case Anxiety Scale - Trait, Journal of Psychological and Educational Sciences. 4 (1). Q: 77-100. Published by the University of the Martyr Hamma Lakhdar in the Valley - Algeria.

Greffman, E, (1963). Stigma: Notes on the management of spoiled Identity, Englewood cliffs, NJ: prentice-hell .

Heredia Montesinos, A, Rapp (2014). The impact of the stigma attached to depression and stress overall and somatization among female Turkish immigrants. European Psychiatry, (27). 522-526. https://doi.org/10.1016/s0924-

9338(12)75704-8

Hinshaw, Stephen (2007). The mark of sham: stigma of mental illness and an agenda for change, Oxford University press, New Yourk.

Immordino \& F.F. Russo (2017). Laws and Stigma: The Case of Prostitution, Center for studies in Economic and finance, working paper. No.338

Itai Mafal \& S.M. Kang (2016). A Critical Review of the Prostitution Phenomenon, Drawing Examples from Selected Countries in the Globe: A Literature Review. Journal of Sociology Anthropology, 7(4). 279-288. https://doi.org/10.31901/24566764.2016/0 7.04 .12

Jack K. Martin (2017). The Stigma Complex, Department of Sociology-, Indiana University, Bloomington, Indiana. Annu. Rev. Social. 41:87-116

Joan M. Blakey \&Alana Gunn, (2019). The "iciness factor": Stigma as a barrier to exiting prostitution, Journal of Offender Rehabilitation. 57(8). 538-561. https://doi.org/10.1080/10509674.2018.154 9177

Jolanda sallmann (2010). Living with Stigma: Women's Experiences of Prostitution and Substance Use. Journal of Homosexuality, 53, 201-217. Google Scholar.

Joseph D.Wellmanay \&.Araizab Crystal and Solanoa Eric. (2019). Sex differences in the relationships among weight stigma, depression, and binge eating journal of Appetite. 133(1). 166-173. https://doi.org/10.1016/j.appet.2018.10.029

Judith Still. (2014). Identifying effective social work practices in response to prostitution, Lund, 21st May, Master of Science in Gender Studies.Lund University.

Kathleen .R. (2013).Discourse, Stigma, and Identity Construction in the Sex Work Community. PhD of Philosophy. Arizona State University.

Kidir, Bayah, A (2011). Original Paper Vulnerability, life events and depression amongst Moslem Malaysian woman: comparing those married and those divorced or separated. Soc Psychiatry Psychiatric Epidermal, (46). 853-862. https://doi.org/10.1007/s00127-010-0249-4

Lawrence H, (2007). Culture and stigma: Adding moral experience to stigma theory, Social Science \& Medicine. Volume 64, Pp 1524-1535.

https://doi.org/10.1016/j.socscimed.2006.11 .013

Lisa Townsend (2019). Gender Differences in Depression Literacy and Stigma after a Randomized Controlled Evaluation of a Universal Depression Education Program. Journal of Adolescent Health, 64(4). 472 477.

https://doi.org/10.1016/j.jadohealth.2018.1 0.298 
International Journal of Childhood, Counselling, \& Special Education (CCSE), Volume1, Issue: 1 , September: 2020, pp.11-38

Lorenz, F.O \& Wickrama, K, A (2006). The short- term and decade-long effects of divorce on woman midlife health, Journal of Health and social Behavior, 47 (2), 111 . 125.

https://doi.org/10.1177/0022146506047002 02

Mclntire, S.A. \& Miller, L.A (2000) Foundations of Psychological testing. New. McGraw. Hill .

Mond, JM. \& Robertson, G (2006). Stigma and eating disorder: Is there evidence of negative attitudes towards anorexia nervosa among woman in the community? Journal of Mental Health. 15 (5), 519-532. https://doi.org/10.1080/0963823060090255 9

Monica R, Alessandra R, Marcella R (2016). Denying Psychological Properties of Girls and Prostitutes, the Role of Verbal Insults, Journal of Language and Social Psychology. V (19), - pp 111-143.

Muhammad, Najia Ishaq (1984). Prostitution and the psychology of the individual. Master's Thesis, Unpublished: College of Arts. Ain-Shams University.

Mumahs, Hatem Soliman (2018). The stigma of mental illness and its relationship with affirmative in the light of some variables, Master Thesis, Faculty of Education. Islamic University of Gaza.

Nicoline Schiess \& Katherine Huether \&, Kathryn B. Holroyd \& Faisal Aziz \& Essam Emam \& Tarek Shahrour \& Miklos Szolics $\&$ and Taoufik Alsaadi,(2019). Multiple Sclerosis, Anxiety, and Depression in the United Arab Emirates, Does Social Stigma Prevent Treatment? International Journal of MS Care. 21(1). 29-34. https://doi.org/10.7224/1537-2073.2017-041

Rachel M\&Melissa F, (2019). Consent, Coercion, and Culpability: Is Prostitution Stigmatized Work or an Exploitive and
Violent Practice Rooted in Sex, Race, and Class Inequality? Archives of Sexual Behavior. pp 1-7.

Raheem, Hind Sobeih (2016). Building a statistical anxiety scale and applying it to Baghdad University students, Professor's Journal. AR (219), Volume II. Ibn Rushd. Faculty of Education, University of Baghdad. Iraq

Saati, Samia Hassan (1983). Crime and society. Beirut: Arab Renaissance House.

Schmitt, S., Euchner, E., Preidel, C. (2013), Regulating Prostitution and SameSex Marriage in Italy and Spain: The Interplay of Political and Societal Veto Players in Two Catholic Societies. Journal of European Policy, 20(3). 425-441. https://doi.org/10.1080/13501763.2013.761 512

Sydney H. Kinnear, B. G. (2016). Understanding the Experience of Stigma for Parents of Children with Autism Spectrum Disorder and the Role Stigma Plays in Families' Lives, Journal of Autism and Developmental Diso, 46(3). 492-953. https://doi.org/10.1007/s10803-015-2637-9

World Health Organization (2004). Mental health care in devolving countries: a critical assessment of the research results, the report of a study group of the World Health Organization (meeting held in Geneva from 15 to 21 September). 